\title{
Reorganização Econômica, Absorção de Mão de Obra e Qualificação ${ }^{1}$
}

\author{
Economic Reorganization, Labor \\ Absorption and Qualification
}

CLAUDIO SALVADORI DEDECCA ${ }^{2}$

\begin{abstract}
RESUMO: Nos anos 90, a sociedade brasileira conheceu um processo muito importante de mudanças econômicas e sociais. Após um longo período de desenvolvimento centrado no mercado interno e na base industrial local, foi adotada uma nova política econômica visando o aumento da competitividade da estrutura industrial. A nova dinâmica econômica induziu o crescimento da importação e reduziu a importância da base produtiva local para o nível do mercado interno. Essa dinâmica impôs reduções sistemáticas do nível formal de emprego. O governo argumenta que os problemas de emprego são explicados pelo nível reduzido de qualificação dos trabalhadores nacionais. Este artigo mostra que essa dinâmica se baseia na força de trabalho não qualificada. Reforça a baixa habilidade do mercado de trabalho brasileiro e não melhora a competitividade da base produtiva nacional. Não encontramos indicadores capazes de confirmar os argumentos da política econômica real. PALAVRAS-CHAVE: Mercado de trabalho, qualificação, indústria, competitividade.
\end{abstract}

ABSTRACT: In the 90's, the Brazilian society knew a very important process of economic and social changes. After a long period of the development centered in the internal market and local industrial base, a new economic policy was adopted aiming increase to the competitiveness of the industrial structure. The new economic dynamic induced the growth of the importation and reduced the importance of local productive base for internal market level. This dynamic has imposed systematic reductions of the formal employment level. The government argues that the employment problems are explained by the reduced level of the qualification of national workers. This paper shows that this dynamic is based in the unskilled labor force. It reinforced the low skill of the Brazilian labor market and doesn't

\footnotetext{
${ }^{1}$ Este ensaio apresenta alguns resultados da pesquisa Reorganização Produtiva e Estrutura de Emprego no Brasil: os anos 90, que contou com o apoio do CNPq e da Fapesp. O autor gostaria também de agradecer as sugestões feitas pelos pareceristas. Esclarece ainda que, devido às justificadas orientações editoriais, diversas tabelas e gráficos foram suprimidos em favor da maior clareza da análise e dos argumentos desenvolvidos.

${ }^{2}$ Professor do Instituto de Economia da Unicamp. E-mail:claudio.dedecca@eco.unicamp.br.
} 
improve the competitiveness of national productive base. We don't find indicators able to confirm the arguments of the actual economic policy.

KEYWORDS: Labor market, qualification, industry, competitiveness.

JEL Classification: J12, J13, O25.

Este ensaio analisa as novas condições de absorção de mão-de-obra no Brasil a partir da década de 1990, as quais têm sido caracterizadas por uma crescente informalidade do mercado de trabalho não-agrícola, bem como pela reprodução de um desemprego ponderável. A reconfiguração em curso do mercado de trabalho nacional tem implicações para o presente e o futuro. Suas novas condições de funcionamento têm efeitos tanto econômicos como sociais. Este trabalho apresenta uma interpretação desse processo, mostrando que a crescente informalidade e desemprego associam-se a uma nova dinâmica da economia brasileira. Ademais, aponta que a reorganização não vem produzindo a elevação do perfil de qualificação da mãode-obra. Essa nova dinâmica deverá, portanto, aprofundar o caráter heterogêneo e desigual da sociedade e economia brasileiras.

\section{O DESENVOLVIMENTO CENTRADO NA INDUSTRIALIZAÇÃO E NO MERCADO INTERNO - 1930-80}

A crise de 1930 forçou a consolidação de uma base industrial e do desenvolvi-mento do mercado interno no país, orientada por uma industrialização sustentada, até os anos 50, nos setores têxtil e alimentício. O desenvolvimento do mercado interno foi requerendo um aparelho de Estado mais complexo, em razão das novas funções públicas, e setores terciários, bancário e de distribuição, necessários ao desenvolvimento do mercado interno (Singer, 1971 e Almeida, 1974).

Na segunda metade dos anos 50, o padrão de industrialização passou por um período de rápida transformação, com a implantação das indústrias de bens de produção e de duráveis (Plano de Metas), que permitiu uma melhor consolidação da produção e do mercado de trabalho nacionais. Entretanto, o mercado de trabalho no final daquela década continuava a ter pouco mais de $50 \%$ da população economicamente ativa inserida nas atividades não-agrícolas (Baltar \& Dedecca, 1995). O emprego industrial mantinha-se minoritário na estrutura urbana de ocupações.

Após um período de crise entre 1961 e 1966, a economia conhece um movimento de rápida expansão até 1973-74, quando se inicia um período marcado pela desaceleração do crescimento, que não foi mais acentuada devido ao papel exercido pelo Estado na sustentação da taxa de formação bruta do capital fixo provocada pelo II Plano Nacional de Desenvolvimento Econômico (II PND). Entretanto, o esgotamento das condições de financiamento desse investimento plasmou, pela primeira vez, uma crise do padrão de crescimento econômico do pós30, 
em razão do processo ter no endividamento externo uma fonte importante de financiamento.

A crise externa do início dos anos 80 foi enfrentada com uma política econômica fortemente restritiva, que provocou um movimento recessivo abrupto e a emergência de um novo fenômeno no mercado de trabalho urbano: o desemprego aberto (Sabóia, 1986). Apesar de o emprego industrial haver alcançado uma extensão limitada na estrutura ocupacional brasileira, em 1980, é inquestionável que a referência básica para a organização do mercado nacional de trabalho, no período 193070, passara a ser o assalariamento na grande empresa. O desdobramento da estrutura produtiva moderna induzia o crescimento sistemático do emprego assalariado. Na década de 1970, ao contrário das previsões pessimistas do final dos anos 60, constatou-se que aquele padrão de desenvolvimento havia apresentado uma grande capacidade de geração de novos empregos. O processo de desenvolvimento não se traduziu em uma maior estruturação do mercado urbano de trabalho devido ao aumento exponencial da disponibilidade de força de trabalho nas cidades, causado por uma modernização agrícola que havia relegado a solução do problema agrário, ao mesmo tempo que criava um fluxo migratório incompatível com a capacidade de geração de novos empregos no meio urbano (Souza, 1980; e Salm \& Eichenberg, 1989).

Durante o período de crescimento, o excedente de força de trabalho foi sendo absorvido em atividades urbanas no setor terciário tradicional, em especial no emprego doméstico e nos serviços pessoais. O crescimento sustentado do emprego assalariado permitiu consolidar essa forma de relação de trabalho e transformar o mercado urbano de trabalho, fazendo com que, apesar da elevada rotatividade observada, a mão-de-obra não encontrasse maiores restrições para se reempregar.

As atividades consideradas modernas (capitalistas) mantinham relações tênues com as atividades atrasadas (sobrevivência), através do circuito de renda-consumo (Souza, 1980 e Cacciamali, 1983). As atividades capitalistas apareciam como um núcleo autônomo que tinha capacidade de se reproduzir ampliada e rapidamente, bem como de sustentar uma gama de atividades de baixa produtividade, na qual se inseria o excedente de força de trabalho com tradição recente no meio urbano. Esse processo era reforçado pela desfavorável distribuição de renda que viabilizava a reprodução de formas de consumo que alimentava todo um conjunto de atividades de serviços pessoais e o emprego doméstico.

A modernização consolidava uma estrutura produtiva e um segmento de mercado de trabalho comandado pelas grandes empresas e o setor público, ao mesmo tempo que alimentava uma gama de atividades econômicas não sustentadas pelo trabalho assalariado ou nele amparadas por relações precárias, ampliando tanto a heterogeneidade econômica como a social (Dedecca, 1990; e Henrique, 1999). A ação repressiva dos governos autoritários, recorrente no período, impedia que a organização política da sociedade pudesse alterar os efeitos sociais desfavoráveis que caracterizam o processo de modernização. 


\section{DE 1980 AOS DIAS DE HOJE}

O esgotamento daquele padrão de desenvolvimento foi seguido pela reconfiguração da estrutura produtiva e do mercado de trabalho e das inter-relações entre seus segmentos de atividades e ocupacionais (Dedecca \& Baltar, 1998), movimento que ganha velocidade na década de 1990 .

A evolução divergente entre produção e emprego aparece como uma das ca-racterísticas das novas condições de estruturação da base produtiva, situação que é acentuada pela nova política econômica dos anos 90, ancorada na abertura externa rápida e abrupta com eliminação de parte da capacidade produtiva. Plasma-se uma redução do emprego assalariado nas grandes empresas, que joga para o desemprego e para as pequenas e médias atividades importantes contingentes de força de trabalho. O chamado setor informal deve absorver tantos os novos contigentes de migrantes que chegam ao meio urbano, como os assalariados expulsos pelo setor formal.

Ademais, a desverticalização com subcontratação conduzida pelas grandes empresas e o aumento ponderável da importação de parte do consumo industrial impuseram a extinção de postos de trabalho e a ampliação, de maneira sistemática, das relações produtivas das mesmas com as pequenas e médias empresas, tornando ainda mais complexas as inter-relações entre ambos os segmentos básicos da atividade econômica. O pequeno e médio setor tem seu papel na dinâmica econômica transformado, ampliando as articulações com as grandes empresas de seu segmento contratado .

O limitado incremento do produto, em um contexto de reorganização da estrutura produtiva com aumentos ponderáveis da produtividade e de vazão de parte da renda para o setor externo, promoveu um movimento de racionalização econômica e, por conseqüência, do mercado de trabalho. A esse comportamento do segmento privado sobrepõe-se a contenção dos gastos correntes e dos investimentos do Estado, em razão da necessidade que tem este de dirigir prioritariamente os ganhos de receitas para o pagamento dos crescentes encargos impostos pela política monetária.

Essa nova dinâmica reconfigura as relações entre o setor capitalista e o setor informal, ao tornar recorrentes as relações de produção entre eles. As novas condições de funcionamento da economia e do mercado de trabalho modificam substancialmente as relações entre os diversos segmentos de atividade. Essa alteração tende a consolidar um pequeno-médio setor articulado economicamente que tem sua atividade produtiva dirigida e subordinada à dinâmica do grande setor (Dedecca, 1998).

\footnotetext{
${ }^{3}$ A divergência entre as evoluções da produção e do emprego é acentuada, ainda, pela substituição de parte do insumos industrializados nacionais por aqueles de origem estrangeira.
} 


\section{DESEMPENHO E ESTRUTURA DO MERCADO DE TRABALHO}

Nos anos 90, observa-se a continuidade da queda do crescimento da População em Idade Ativa ${ }^{4}$, com taxas mais baixas para as Regiões Sudeste e Sul e significativamente mais elevada para a Região Nordeste. Influenciada ainda pelas altas taxas de natalidade do passado e pelo aumento da taxa de participação, particularmente determinada pela maior presença da mulher, a População em Idade Ativa (PIA) cresceu ainda em um ritmo mais rápido de que aquele da População Total (PT). O crescimento da PEA mantém-se ainda mais intenso na área urbana, em razão dos efeitos decrescentes mas ainda ponderáveis da migração rural-urbana. Apesar da tendência de queda das taxas de crescimento da PIA e da PEA, elas se mantiveram, para os anos 90, superiores àquelas observadas para a População Ocupada (1,3\% a.a.), traduzindo-se em uma elevação do desemprego a taxas significativas.

Tabela 1: Taxas Anuais de Crescimento da População em Idade Ativa Brasil, Nordeste, Sudeste e Sul, 1990-97

\begin{tabular}{ccccc}
\hline & Brasil & Nordeste & Sudeste & Sul \\
\hline PIA & $1.9 \%$ & $2.1 \%$ & $1.5 \%$ & $1.6 \%$ \\
Pop. Inativa & $1.8 \%$ & $1.9 \%$ & $1.4 \%$ & $1.5 \%$ \\
PEA & $2.1 \%$ & $2.4 \%$ & $1.6 \%$ & $1.6 \%$ \\
$\quad$ Pop. Desempregada & $15.0 \%$ & $15.1 \%$ & $13.8 \%$ & $15.2 \%$ \\
Pop. Ocupada & $1.3 \%$ & $1.7 \%$ & $0.8 \%$ & $1.0 \%$ \\
Pop. Ocup. Agrícola & $-0.2 \%$ & $1.2 \%$ & $-1.1 \%$ & $-3.0 \%$ \\
Pop. Ocup. Não-Agrícola & $1.8 \%$ & $2.0 \%$ & $1.1 \%$ & $2.5 \%$ \\
GMS & $-0.9 \%$ & $-0.3 \%$ & $-1.7 \%$ & $0.2 \%$ \\
PMS-C & $6.9 \%$ & $4.1 \%$ & $7.1 \%$ & $8.7 \%$ \\
PMS-NC & $4.5 \%$ & $3.9 \%$ & $4.4 \%$ & $4.7 \%$ \\
\hline
\end{tabular}

Fonte: Pesquisa Nacional por Amostra de Domicílios, PNAD, Microdados, Elaboração Própria.

O aumento da População Ocupada ocorreu predominantemente nas atividades não-agrícolas, havendo uma certa estabilidade da parcela vinculada às atividades agrícolas. Mesmo assim, 13,5 milhões de pessoas continuavam, em 1997, vinculadas às atividades agrícolas, sendo quase 7 milhões na Região Nordeste.

Quanto à ocupação não-agrícola, nota-se que os anos 90 foram marcados por

\footnotetext{
${ }^{4}$ A avaliação das transformações do mercado de trabalho brasileiro, nos anos 90, adotará duas fontes básicas de dados. A partir da Pesquisa Nacional por Amostra de Domicílios, PNAD-IBGE, serão enfocadas as mudanças ocorridas nas condições de participação e ocupação da população em idade ativa. Como complemento a essa abordagem mais abrangente, serão analisadas as alterações no emprego formal - isto é, com carteira de trabalho assinada - mensurado pela Relação Anual de Informações Sociais, RAIS-MTE.
} 
uma contração do emprego assalariado nos estabelecimentos de maior porte, segmento que denominamos de Grande-Médio Setor (GMS) $)^{5}$. O comportamento desse segmento ocupacional não foi ainda mais negativo graças ao crescimento do emprego público associado ao desenvolvimento da política social induzido pela Constituição Nacional de 1998.

Gráfico 1:Evolução da Estrutura Ocupacional

Brasil, Nordeste, Sudeste, Sul — 1990, 95 e 97

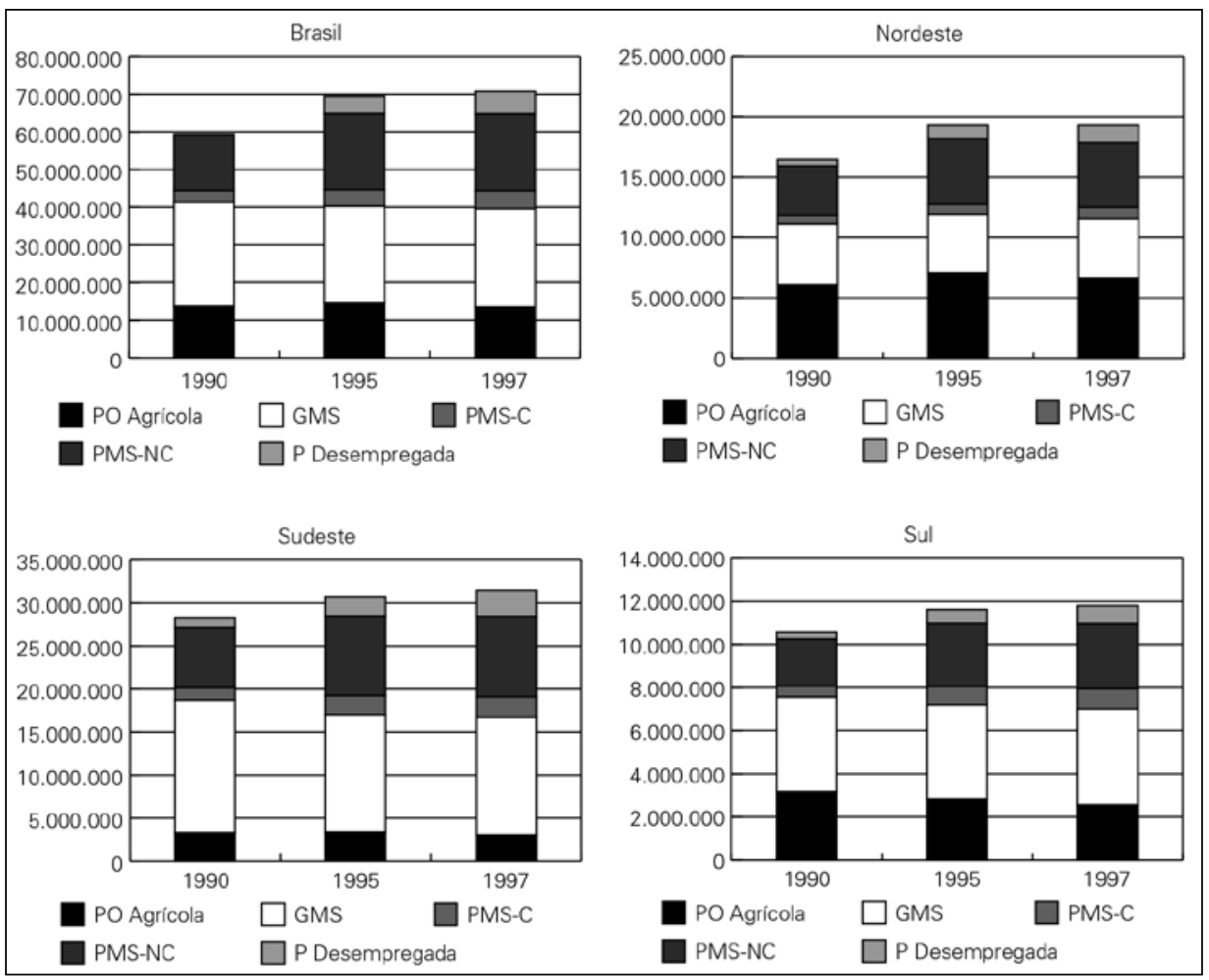

Fonte: Pesquisa Nacional por Amostra de Domicílios, PNAD, Microdados, Elaboração Própria.

\footnotetext{
${ }^{5}$ Adotando critério internacionalmente aceito, oriundo dos trabalhos da Organização Internacional do Trabalho, diferenciou-se inicialmente os estabelecimentos com menos e com mais de 5 empregados. A partir dessa classificação, explorou-se o destino do trabalho dos trabalhadores autônomos e dos assalariados em estabelecimentos com menos de 5 empregados. Os assalariados formais em estabelecimentos com mais de 5 empregados, os empregadores desses estabelecimentos e os profissionais liberais foram classificados como pertencentes ao Grande-Médio Setor; os assalariados em estabelecimentos com menos de 5 empregados e os autônomos que destinam seu trabalho para algum outro estabelecimento foram agrupados no Pequeno-Médio Setor Contratado; e os assalariados em estabelecimentos com menos de 5 empregados e os autônomos que trabalham para os domicílios e as pessoas foram incorporados ao Pequeno-Médio Setor Não-Contratado. Essa possibilidade de classificação tornou-se possível graças à metodologia adotada pelo IBGE para a Pesquisa Nacional de Amostra de Domicílios nos anos 90.
} 
A reorganização econômica foi marcada pela ampliação do Pequeno-Médio Setor, tanto de seu segmento vinculado à atividade econômica do GMS, como daquele orientado para o consumo das famílias. Apesar do crescimento substantivo de ambos segmentos, foi o Pequeno-Médio Setor Não-Contratado (PMS-NC) aquele que se constituiu em locus privilegiado de absorção de mão-de-obra. Nove de cada 10 novas oportunidade de trabalho criadas entre 1990 e 1997 foram no PMS-NC. Essas características são recorrentes em todas as regiões brasileiras analisadas, independentemente do grau de desenvolvimento industrial de cada uma delas.

Não parece haver indícios que pudessem corroborar a idéia de que os problemas do desemprego e da informalidade possam estar associados à crise de emprego industrial. Ambos os problemas se manifestaram na Região Nordeste, que passou a conviver com um desemprego explícito que se soma com aquele da informalidade estruturalmente ali presente. Portanto, o baixo dinamismo com contração da base de trabalho assalariado do GMS, em um mercado de trabalho com um crescimento da População Economicamente Ativa ponderável, foi acomodado mais uma vez pela informalidade, mas também pelo desemprego. Enquanto o GMS tinha seu estoque de ocupados reduzido de 27,6 para 26 milhões de pessoas, entre 1990 e 1997, o PMS-C e o PMS-NC tinham seus estoques incrementados de 3,0 para 4,8 milhões e 14,9 para 20,3 milhões, respectivamente.

Analisando o aumento do total da ocupação não-agrícola por setor de atividade, notamos que quase $60 \%$ ocorreu no Terciário para Pessoas/Famílias e $20 \%$ no Terciário para a Comunidade. Na Região Nordeste, esses setores responderam, respectivamente, por $68 \%$ e $17 \%$, na Sudeste por $76 \%$ e $29 \%$ e na Sul por $37 \%$ e $11 \%$. Apesar de considerável, a contribuição do Terciário para Empresas foi significativamente mais baixa.

Merece menção o comportamento do emprego industrial na Região Sul, que apresentou uma trajetória de crescimento no período. Esse movimento contraria a visão sobre a inevitabilidade da queda do emprego industrial.

Se tomarmos a escolaridade como uma proxy da qualificação, constatamos que a absorção de trabalhadores continua se dando particularmente para os trabalhadores menos escolarizados. Esse fenômeno não aparece de maneira mais explícita devido à contração do emprego no GMS ter se concentrado fortemente nos trabalhadores com o $1^{\circ}$ Grau Incompleto. Enquanto o GMS expulsou trabalhadores com baixa escolaridade, o PMS-NC permitia uma incorporação apreciável desses. Independentemente da Região Geográfica, 2/3 das pessoas absorvidas no PMS-NC tinham no máximo o $1^{\circ}$ Grau Completo. Deve-se considerar, entretanto, a importância do aumento da ocupação das pessoas com $2^{\circ}$ Grau Completo, que atingiu $52 \%$ das novas oportunidades de trabalho e que teve no GMS seu espaço privilegiado. Como se verá mais à frente, esse movimento parece ter estado relacionado a um política de contratação seletiva das empresas como parte de seus processos de reorganização.

O processo de absorção foi concentrado nas classes de idade de 25 a 54 anos e entre os chefes de família e cônjuges, indicando uma maior dificuldade de inserção dos jovens/filhos. Essa dificuldade de absorção atingiu também aqueles com idade 
mais avançada. Tudo indica que tenha havido um acirramento da concorrência pelas oportunidades de trabalho entre aqueles com alguma experiência profissional e em faixa de idade considerada mais produtiva. Essa é uma característica que também se reproduz em todas as regiões geográficas.

Essa maior competição deve ter também se manifestado entre sexos. As mulheres tiveram um crescimento mais rápido na PEA e também na População Ocupada. Entretanto elas contribuíram mais para o desemprego que os homens. Se, por um lado, elas conseguiram um maior número de oportunidades de trabalho, por outro, o crescimento mais rápido da PEA específica jogou mais intensamente as mulheres para o desemprego. Esse perfil da incorporação da mulher ao mercado de trabalho é mais visível na Região Sudeste, onde o desemprego e o PMS-NC cresceram mais intensamente.

Tabela 2: Contibuição por Gênero para a Variação Total da População Economicamente Ativa Brasil, Nordeste, Sudeste e Sul, 1990-97

\begin{tabular}{lcccc}
\hline & Brasil & Nordeste & Sudeste & Sul \\
\hline PEA & $100 \%$ & $31 \%$ & $35 \%$ & $13 \%$ \\
Total & $40 \%$ & $13 \%$ & $13 \%$ & $4 \%$ \\
Homem & $60 \%$ & $18 \%$ & $22 \%$ & $10 \%$ \\
Mulher & $39 \%$ & $10 \%$ & $18 \%$ & $6 \%$ \\
$\begin{array}{l}\text { Desempregados } \\
\text { Total }\end{array}$ & $15 \%$ & $3 \%$ & $7 \%$ & $2 \%$ \\
Homem & $24 \%$ & $6 \%$ & $11 \%$ & $4 \%$ \\
Mulher & $61 \%$ & $21 \%$ & $17 \%$ & $8 \%$ \\
Ocupados & $25 \%$ & $10 \%$ & $6 \%$ & $2 \%$ \\
Total & $35 \%$ & $11 \%$ & $11 \%$ & $6 \%$ \\
Homem & Mulher & & & \\
Muln
\end{tabular}

Fonte: Pesquisa Nacional por Amostra de Domicílios, PNAD, Microdados, Elaboração própria

Tabela 3: Evolução do Emprego Formal Não-Agrícola Brasil, 1986, 89, 92 e 96

\begin{tabular}{lcccc}
\hline & 1986 & 1989 & 1992 & 1996 \\
\hline Total & 100,0 & 100,1 & 91,1 & 93,5 \\
Indústria de Transformação & 100,0 & 102,4 & 78,7 & 81,1 \\
Serviços de Utilidade Pública & 100,0 & 108,2 & 109,6 & 123,7 \\
Comércio & 100,0 & 110,5 & 85,6 & 108,9 \\
Serviços & 100,0 & 112,0 & 100,1 & 104,1 \\
Administração Pública e Ensino & 100,0 & 107,6 & 96,8 & 126,7 \\
\hline
\end{tabular}

Fonte: Relação Anual de Informações Sociais, RAIS. 


\section{A EVOLUÇÃO DO EMPREGO FORMAL ${ }^{6}$}

O emprego formal durante os anos 90 teve sua participação relativa reduzida na composição da ocupação global. No período 1989-96, observou-se uma forte contração do nível de emprego, com a eliminação de 1,4 milhão de postos de trabalho. Esse movimento foi particularmente determinado pela diminuição de postos de trabalho na Indústria de Transformação (1,4 milhão) e no Setor Financeiro (400 mil). Os Serviços de Utilidade Pública (43 mil) e a Administração Pública e Ensino (937 mil) tiveram tendências positivas, mas insuficientes para compensar o efeito negativo dos dois outros setores apontados.

A recuperação da economia nacional entre 1992 e 1995 possibilitou uma recomposição parcial do nível de emprego, com a criação líquida de cerca de 500 mil novos postos de trabalho. Os setores que tiveram uma melhor performance foram a Administração Pública e Ensino (1,5 milhão), o Comércio (452 mil) e os Serviços (206 mil). Entretanto, o comportamento conjunto desses setores foi insuficiente para compensar as quedas observadas entre 1989 e 1992, fazendo com que o nível de emprego continuasse inferior ao encontrado em 1989.

Um aspecto que salta aos olhos é a ausência de indícios sobre uma possível mobilidade inter-setorial de trabalho assalariado - da indústria para o terciário. O crescimento do emprego desse setor não superou o incremento da População Economicamente Ativa, situando-se próximo ao patamar mínimo de ampliação do setor terciário. Não há maiores indícios de que as atividades modernas de serviços, excluindo-se a Administração Pública e Ensino, estejam sendo loci relevantes de absorção e de sustentação do nível de emprego formal.

Essa contração do nível de emprego formal ocorrida nos primeiros anos da década de 1990 teve como alvo a demissão dos trabalhadores menos qualificados, em especial aqueles com baixo nível educacional e menor tempo de serviço (Dedecca \& Rosandiski, 1997).

\footnotetext{
${ }^{6}$ A avaliação da evolução do emprego formal utiliza os dados da Relação Anual de Informações Sociais, RAIS-MTE. A adoção dessa fonte de informações deve-se à possibilidade de um melhor tratamento das modificações da estrutura ocupacional. A declaração de vínculo empregatício realizada pela empresa apresenta, em geral, uma melhor qualidade das informações sobre ocupação exercida, o setor de atividade da empresa, o tamanho do estabelecimento. Como a análise tem na avaliação da estrutura de emprego um enfoque privilegiado, os dados da RAIS possuem vantagens indiscutíveis - ver Dedecca, 1996. Entretanto, a melhor qualidade da informação impede que se mantenha a classificação setorial construída anteriormente com os dados da PNAD, pois são ausentes na RAIS as informações sobre o destino da produção de cada estabelecimento/ocupado. Além disso, a classificação setorial anteriormente adotada não pode ser compatibilizada com as informações sobre desempenho econômico. Nesse sentido, adotase a classificação setorial mais tradicional, sendo posteriormente detalhada a discussão para a Indústria de Transformação. Também merece menção que a análise sobre o emprego formal é desenvolvida para o conjunto do país, em razão da impossibilidade de realizar o detalhamento regional adequado no espaço deste ensaio.
} 


\section{DESEMPENHO ECONÔMICO, EMPREGO E QUALIFICAÇÃO: O CASODA INDÚSTRIA DE TRANSFORMAÇÃO}

É indubitável que a melhora do perfil da estrutura de ocupações da indústria de transformação pode favorecer a produtividade, o emprego, os salários e a competitividade. Quanto ao emprego, seu comportamento dependerá do crescimento setorial. Os salários estarão associados ao aumento da produtividade e do nível de produção. A produtividade depende do padrão de investimento e de financiamento articulado com a reorganização produtiva. Esse padrão pode ampliar as relações inter-setoriais, induzir a modernização tecnológica, fortalecer as políticas de gestão de mão-de-obra e financiar a produção intermediária e final, os investimentos e a qualificação profissional. A elevação da produtividade em um contexto de aumento da produção atua positivamente sobre a competitividade do setor industrial e de toda a economia brasileira. O padrão de investimentos e financiamentos encontra-se relacionado às políticas econômica e industrial, mas particularmente à concepção de eficiência que orienta cada uma delas.

Os indicadores macroeconômicos, mostram uma divergência entre o comportamento do PIB total e aquele do setor industrial entre 1987 e 1992, marcada pela redução da contribuição da indústria para o PIB total. A perda de participação do PIB industrial é interrompida a partir de 1993. Entretanto, a manutenção sistemática da distância entre as duas curvas e o desempenho mais favorável do PIB do Setor de Serviços sugere que, desde então, a estrutura produtiva brasileira conta com uma participação mais substantiva da componente importada, a qual cresce, ao menos proporcionalmente, ao incremento do PIB industrial. Assim, a nova dinâmica industrial carrega consigo maiores relações com a economia internacional, menos pela variável exportação e principalmente pela importação. Entre 1989 e 1995, ocorrem aumentos mais substantivos na participação das importações no PIB.

Desde 1989, observa-se uma tendência de aumento do peso das importações, que acompanha aquela referente à Formação Bruta de Capital Fixo (FBCF). Se considerado como referência o ano de 1985, nota-se que a taxa de FBCF, em 1997, encontrava-se ainda em um patamar inferior, enquanto a taxa de importações situava-se em um significativamente superior. $\mathrm{O}$ aumento das importações não pode, desse modo, ser imputado à recuperação limitada da FBCF, independentemente de sua composição, devendo ser explicado pelo aumento do consumo dos diversos setores de atividade e da própria população.

Quanto às exportações, o decréscimo de sua participação coincide com a valorização cambial ocorrida a partir de 1992. É completa a relação entre as duas curvas. Se, por um lado, a valorização cambial beneficiou o quantum importado, ela atingiu negativamente o exportado. A possibilidade de manter as exportações, nesse contexto, dependia de um aumento substantivo da produtividade industrial

\footnotetext{
${ }^{7}$ Para uma análise sobre eficiência, ver Penrose (1980), Chandler (1990). Williamson (1991), Lorino (1991), Gordon (1996) e Duval (1998).
} 
e agrícola que compensasse a valorização cambial e pudesse ser transferida para os preços, dando, desse modo, maior competitividade à economia brasileira.

Entretanto, essa possibilidade era reduzida, pois para aumentar a produtividade fazia-se necessário elevar a FBCF, que se realizada teria acelerado ainda mais as importações. Em outras palavras, qualquer taxa de crescimento mais significativa do setor industrial, com o coeficiente de abertura prevalecente desde 1992, levaria a um aumento mais rápido das importações e, por decorrência, da dívida externa, cujo valor já crescia rapidamente devido a seus custos de financiamento. Esse constrangimento impôs um crescimento lento tanto do PIB total como do industrial. Assim, o crescimento do PIB brasileiro foi, depois de 1994, no máximo igual ao conseguido pelos países industrializados.

Gráfico 2: Indicadores Macroeconômicos Brasil — 1985-97

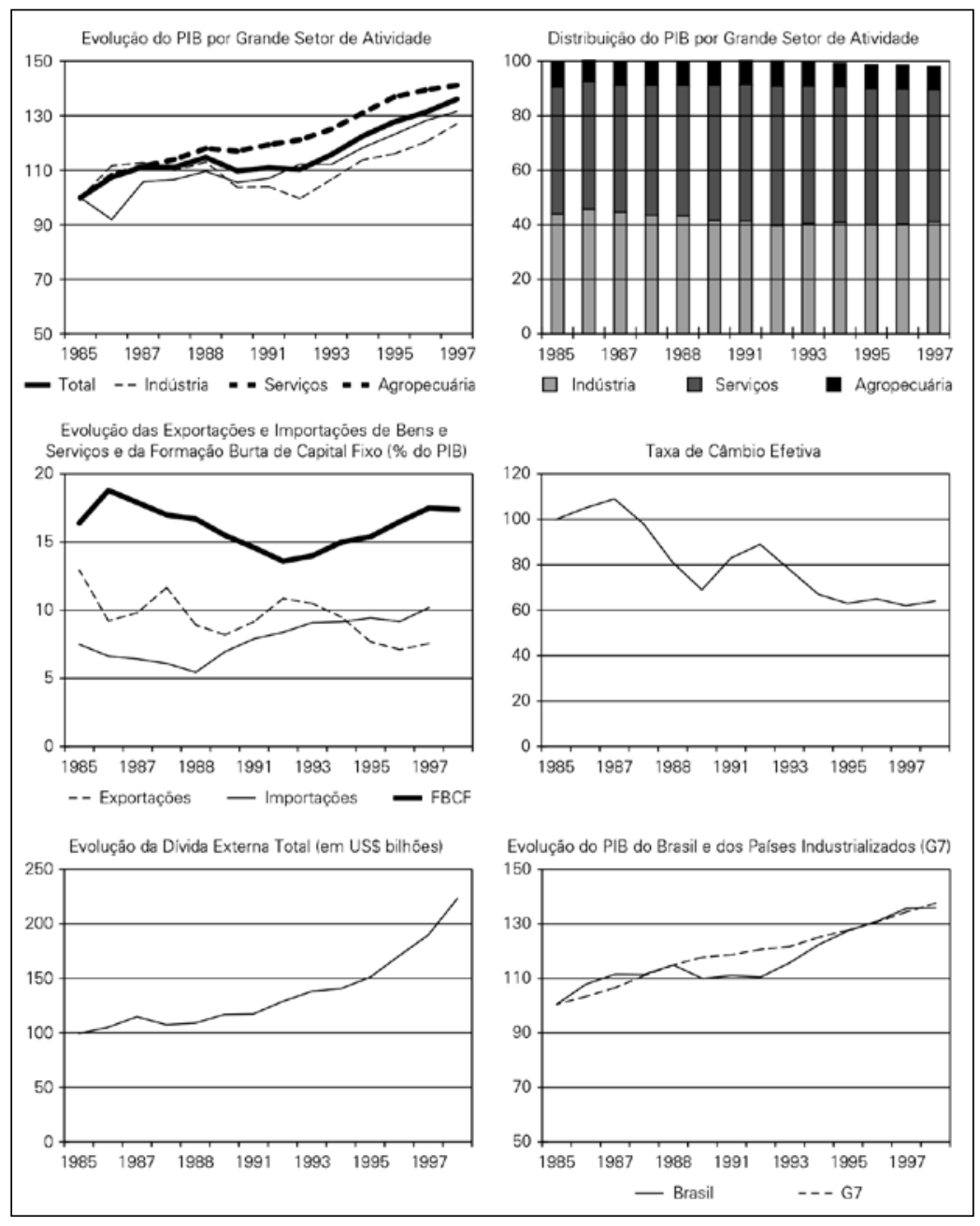

Fonte: IBGE, Contas Nacionais; Conjuntura Econômica, Junho, 1999; Fundap, Indicadores Diesp, 72, maio-junho, 1999; Elaboração Própria. 
Face a esses constrangimentos, os aumentos de produtividade devem ter se apoiado, em especial, na melhoria do uso dos fatores existentes com uma modernização tecnológica restringida. A introdução de inovações organizacionais e a externalização de segmentos menos relevantes da produção ou compra de parte do consumo industrial no mercado internacional, em razão do baixo preço garantido pela valorização cambial, devem ter cumprido um papel importante no aumento da produtividade. As condições internas às empresas passaram, desse modo, a ser identificadas como a fonte da maior competitividade.

A comparação entre a produção física e o PIB mostra um progressivo distanciamento entre as curvas. A quantidade produzida não acompanhou o crescimento do produto interno do país ou, de um outro ponto de vista, o consumo interno. Por outro lado, a estabilidade da produção física é acompanhada por uma aceleração na taxa de crescimento da produtividade física-hora, com reflexos intensos e negativos sobre o pessoal ocupado na produção. Esse comportamento ocorreu de maneira semelhante nos principais segmentos industriais (metal-mecânico, químico e alimentício). A partir de 1994, a produção física tende à estabilidade, excetuando-se a indústria química, que apresenta uma tendência de aumento lento. Independentemente do comportamento da produção física, a produtividade física-hora cresceu rapidamente com efeitos claramente negativos sobre o pessoal ocupado na produção.

O movimento desproporcional entre a FBCF, a produção física e a produtividade física-hora reforça a posição sobre uma a modernização não-associada a incorporação extensa de novos equipamentos. Algumas informações macroeconômicas corroboram esse argumento. Durante esse período, o mercado interno foi fortemente penetrado por produtos importados, a taxa de juros real manteve-se elevadíssima e a produção industrial cresceu lentamente - com exceção de alguns segmentos industriais (automotivo e eletrônica de consumo). Isto é, as condições macro foram desfavoráveis ao processo de investimento e de endividamento. A modernização tecnológica foi viável nos casos que não gerava nem grandes investimentos e nem um grau de endividamento ponderável. Caso ela tivesse ocorrido, o segmento produtor de bens de capital não teria obtido o fraco desempenho observado. Por outro lado, o aumento da produtividade com modernização limitada ampliou o consumo industrial importado, fato evidenciado pelo comportamento medíocre do segmento de bens intermediários.

Os investimentos em capital fixo (CNI/CEPAL, 1997, p. 18; e CNI/SENAI, 1998), em 1995-96, foram principalmente dirigidos para a redução de custos e reposição de equipamentos, tendo obtido importância menor aqueles voltados para ampliação da produção, implantação de novas plantas e lançamentos de novos produtos. A modernização foi orientada, principalmente, para a melhora das condições de utilização da capacidade produtiva existente, fazendo das inovações organizacionais seu campo privilegiado. Estas viabilizaram uma eficiência da produção sem exigência maior por uma modernização tecnológica, permitindo o casamento de gerações bastante díspares de equipamentos (Lorino, 1992 e Dedecca, 1999a) e sem exigir a mobilização de fundos substantivos que pudeseem ampliar 
o risco financeiro da empresa. A modernização fundada em inovações organizacionais permitiu a redução da pressão por inovações tecnológicas mais substantivas. A modernização parece ter resultado, principalmente, em produção com menores custos. A pressão para redução dos custos com mão-de-obra foi amplificada pela valorização cambial, que provocou uma depreciação não justificada da relação câmbio-salário. A apreciação desse indicador, a partir de 1995, ocorreu graças à redução dos salários reais.

O comportamento dos salários no período mais recente encontra-se, portanto, associado às inovações organizacionais. A introdução de novas formas de gestão de mão-de-obra foi acompanhada da adoção de novas normas de regulação do uso do trabalho (Dedecca, 1998). A anualização da jornada de trabalho (banco de horas) e a flexibilização dos salários (participação de lucros e resultados) foram inovações que favoreceram a produtividade do trabalho e, em um contexto de enfraquecimento do poder de barganha dos sindicatos, provocaram uma redução dos salários reais. Esse movimento foi traduzido pela queda da relação massa salarial real e produção física, sugerindo que os aumentos de produtividade foram apropriados dominantemente pelas empresas.

\section{A ESTRUTURA DE OCUPAÇÕES E A QUALIFICAÇÃO}

É indiscutível que as novas condições de funcionamento da economia brasileira vêm imprimindo uma reestruturação da estrutura de emprego formal. A redução em si de seu nível deve já ter provocado uma mudança em sua estrutura. A literatura econômica é abundante em mostrar que as empresas adotam posturas seletivas na demissão de trabalhadores frente a um contexto desfavorável do nível de atividade econômica. Os trabalhadores com menor qualificação tendem a ser demitidos em primeiro lugar, pois a recontratação dos mesmos não gera maiores custos de seleção e treinamento para as empresas. É plausível que a contração do nível de emprego seja acompanhada pela elevação da participação dos trabalhadores com maior qualificação, nível de escolaridade mais elevado e maior tempo de serviço na empresa.

Entretanto, existem grandes dificuldades em conhecer acuradamente essas modificações. A possibilidade de um maior acompanhamento do processo pela sociedade depende dos mecanismos de regulação das relações de trabalho existentes. Tanto nos EUA como na Europa do pós-guerra, as negociações coletivas foram ampliando o campo de conhecimento dos sindicatos sobre o uso da força de trabalho pelas empresas, possibilitando a transferência de informações sobre o uso do trabalho do espaço interno das empresas para o externo, onde atuam os sindicatos e o Estado (Dedecca, 1999b).

$\mathrm{Na}$ experiência brasileira, o local de trabalho sempre foi considerado um campo sob controle total das empresas e, em decorrência, desconhecido pelos sindicatos e o Estado. Somente em situações-limite, quando as condições de trabalho eram claramente ultrajantes, o Estado foi capacitado a agir. A ação pública circunscreveu- 
-se praticamente ao controle do registro em carteira de trabalho, o que tem sido desvalorizado pelo Estado ao longo da década. O desconhecimento pelo Estado e Sindicatos do interior das empresas deve ser associado à presença de governos autoritários, que coibiram forçadamente a atuação política dos Sindicatos no período pós-1930.

A ausência do Estado e dos Sindicatos na relação estabelecida mais diretamente pelas empresas com os trabalhadores manteve completamente opaco o conhecimento do padrão de uso do trabalho. As informações existentes permitiram somente denunciar o caráter autoritário das relações de trabalho, associando-se, recorrentemente, à postura retrógrada da gerência das empresas. Menor importância foi dada ao caráter incipiente de nosso sistema de relações de trabalho, que manteve o caráter privado da relação de trabalho construída no interior das empresas. A falta de informações sempre tornou difícil estratificar os trabalhadores segundo níveis básicos de qualificação, nos moldes da tradição da economia e da sociologia do trabalho estabelecida nos países avançados ao longo do século XX.

A emergência da noção de competência, ocorrida a partir do final dos anos 70, amplificou as restrições impostas a essa conduta. A perda progressiva do conhecimento social sobre o uso privado do trabalho vai reduzindo gradativamente as possibilidades de estratificação da estrutura ocupacional segundo níveis básicos de qualificação. Essa dificuldade é ainda maior na experiência brasileira, diante do grau limitado de organização passada de nosso sistema de relações de trabalho, em especial das negociações coletivas.

Em razão da dificuldade em estabelecer uma metodologia mais definitiva para o tratamento da estrutura ocupacional, este ensaio adotou o procedimento de construção de agrupamentos de ocupações ${ }^{8}$ (Crivisqui, 1998; e Aldenderfer \& Blashfield, 1984), obtidos segundo o método de análise de clusters — denominado Semis. A construção dos agrupamentos (clusters) de ocupações foi desenvolvida a partir das variáveis básicas de escolaridade, tempo de serviço e remuneração médios (Dedecca \& Rosandiski, 1998) para os segmentos metal-mecânico, químico e alimentício.

A escolha desses segmentos deveu-se à importância de cada um deles para a dinâmica industrial. O segmento alimentício, com uma participação elevada do trabalho de baixa qualificação, conheceu nos anos 90 um processo de concentração e internacionalização substantivo, com alterações importantes no processo industrial e na organização de seus mercados (BNDES, 1999). Sua dinâmica encontra-se atrelada ao crescimento da população e da renda. O químico também vem também conhecendo uma progressiva concentração e internacionalização, tendo uma heterogeneidade tecnológica e de tamanho razoável. O comportamento do setor tem no consumo intersetorial seu determinante principal. Quanto ao metal-mecânico, duas indústrias cumprem um papel-chave na sua dinâmica: material de transporte e material elétrico e eletrônico. A partir de 1992, ambas obtiveram um desempenho

\footnotetext{
${ }^{8} \mathrm{O}$ exercício resultou na construção de 9 agrupamentos (clusters) ocupacionais. Para efeito de análise e apresentação, eles foram reagrupados em 4 estratos ocupacionais.
} 
fortemente positivo, tendo aprofundado as relações entre seus processos produtivos e o mercado internacional, apesar de continuarem destinando predominantemente sua produção ao mercado interno. Ambos os setores dependem da renda interna e possuem grande capacidade de alavancagem da atividade produtiva intersetorial e do conjunto da economia.

A evolução das estruturas de ocupação dos três segmentos industriais mostra que, em todos eles, ocorreu a melhora do perfil de qualificação até 1992. A partir de então, nota-se uma certa estabilidade de cada uma das estruturas. Se considerados os dois primeiros estratos (baixo e baixo-médio), verifica-se um certo incremento da participação conjunta na metal-mecânica e na química. Isto é, as ocupações caracterizadas por níveis mais baixos de escolaridade, salário e tempo de serviço ampliaram, mesmo que limitadamente, sua participação nas estruturas de ocupações de ambos os segmentos.

\section{Gráfico 3: Estrutura de Ocupações segundo Agrupamentos de Qualificação Brasil, 1986/96}

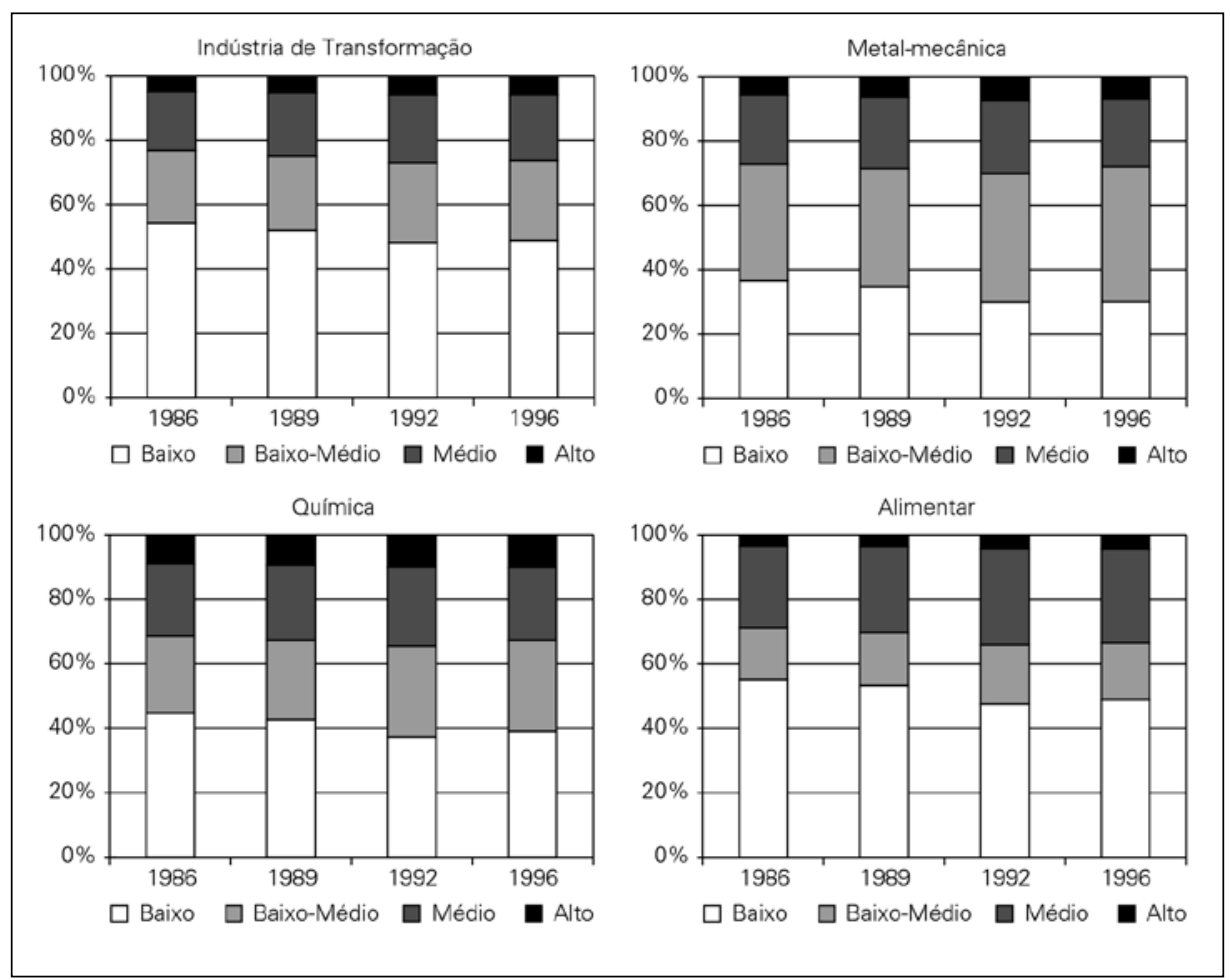

Fonte: Relação Anual de Informações Sociais, RAIS; Elaboração Própria.

Sendo considerados esses dois segmentos como determinantes para a dinâmica industrial e para a competitividade da economia brasileira, a estabilidade relativa da estrutura de ocupações aparece como um fenômeno desfavorável, se considerado o incremento da produtividade observado em cada um deles. Ademais, a estabilidade 
das estruturas de ocupações ocorreu em um contexto de redução do nível de emprego nos dois segmentos industriais, não indicando que as empresas tenham adotado uma política seletiva em favor dos trabalhadores com maior tempo de serviço.

Esse argumento é convergente com os resultados apresentados em estudos anteriores (Dedecca \& Rosandiski, 1997 e 1998), os quais evidenciaram que o aumento da escolaridade média ocorreu predominantemente no interior de cada agrupamento de ocupações, sinalizando que as empresas teriam passado a demandar maior nível educacional para uma mesma ocupação. Ademais, esse movimento foi caracterizado pelo aumento da rotatividade nos momentos de recuperação do nível de atividade, sugerindo que as inovações organizacionais não provocaram o contingenciamento de uma das principais características da política de gestão de mão-deobra das empresas brasileiras.

Gráfico 4: Evolução do Salário Real Mediano em Salários Mínimos Reais de 1998 Brasil, 1986/96

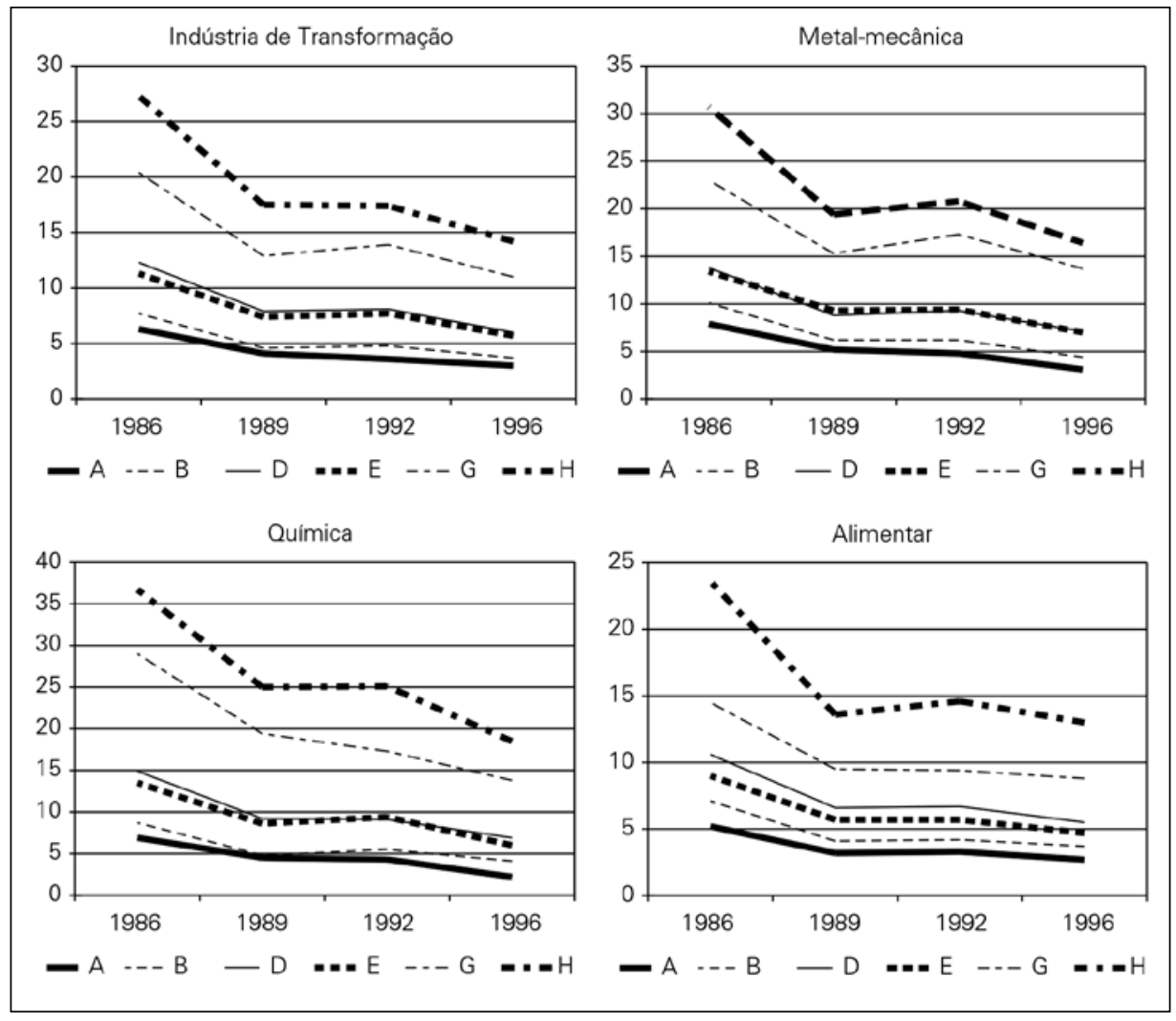

Fonte: Relação Anual de Informações Sociais, RAIS; Elaboração Própria. 


\section{ESTRUTURA DE OCUPAÇÕES E SALÁRIOS}

O último aspecto a ser considerado foi o comportamento dos salários no período 1986-96, que apresentaram a tendência comum de queda de seus valores reais. As perdas mais significativas são observadas entre 1986 e 1989. Entre 1989 e 1992, elas são apenas encontradas para os agrupamentos inferiores, ocorrendo uma abertura do leque salarial. Depois de 1992, reduções do salário real são observadas em todos os segmentos e agrupamentos de ocupações.

O comportamento desfavorável dos salários reais, independentemente do segmento industrial e da qualificação, reforça o argumento anteriormente levantado sobre a apropriação desigual dos ganhos de produtividade obtidos no período. Os resultados da maior eficiência não foram, ao menos em parte, utilizados para transformar as políticas setoriais de gestão de mão-de-obra. A modernização realiza-se conjuntamente a um processo de empobrecimento dos trabalhadores industriais, coerente, inclusive, com a estabilidade da estrutura de ocupações. Afinal, se não há uma melhora substantiva do perfil de qualificação, não existem motivos para que os salários sejam favorecidos em um contexto de elevado desemprego.

\section{CONSIDERAÇÕES FINAIS}

As novas condições dinâmicas da economia brasileira nos anos 90 alteraram as condições de absorção de mão-de-obra. $\mathrm{O}$ enfoque privilegiado na inserção externa, vista como estratégica para a inserção do país no mercado financeiro internacional, impôs um nova dinâmica da economia. Os efeitos desse novo contexto foram, em especial, o emagrecimento forçado de diversos setores industriais, a perda de relações inter-setoriais e a desnacionalização abrupta de segmentos importantes.

A recuperação econômica, observada depois de 1993, foi marcada por uma maior presença de bens e serviços importados, limitando o papel dinâmico do setor industrial. Se, por um lado, a indústria perdeu importância na nova dinâmica da economia, ela, por outro, foi pressionada a uma racionalização produtiva que elevasse seus níveis de produtividade, tendo as inovações organizacionais cumprido um papel decisivo nesse processo. A concorrência feroz em um contexto de baixo crescimento tornou as reduções imediatas de custo a estratégia principal de sobrevivência das empresas. A fragilidade da base produtiva local foi aproveitada pelas empresas internacionais que compraram a baixo preço empresas nacionais ou que aprofundaram as relações de suas plantas locais com as que possuem em outros países com o objetivo de melhorar seu rendimento global. Notou-se, portanto, a prevalência da dimensão microeconômica das empresas, na qual a racionalização de custos foi recorrente. A terceirização, o deslocamento de plantas, o uso de trabalho informal, as inovações organizacionais e a maior flexibilidade das relações de trabalho foram instrumentos valiosos para as empresas, em um contexto de 
modernização tecnológica localizada. Reduções de emprego e de salários acompanharam essa maior eficiência.

Essa racionalização produtiva é coerente com um incremento da produtividade industrial desassociado de uma mudança sistemática e positiva no perfil de qualificação da mão-de-obra. Não existiram razões maiores para que as empresas realizassem investimentos mais substantivos na qualidade da mão-de-obra, pois a capacidade de absorção era muito inferior à disponibilidade existente, sendo essa suficiente para atender o processo de racionalização produtiva.

A reorganização econômica tendeu a jogar sistematicamente contra o emprego e a pressionar para baixo os salários, reforçando o baixo crescimento ao reduzir o poder de compra do conjunto dos assalariados. Em um contexto de crescimento ainda ponderável da PEA, o processo de absorção de mão-de-obra, nessas condições, deve se dar obrigatoriamente através das atividades dependentes de um particular circuito de renda-consumo garantido pela precariedade estrutural de nosso mercado de trabalho e pela perversa distribuição de renda prevalecente no país. A explosão das oportunidades de trabalho no Pequeno-Médio Setor Não-Contratado (PMS-NC) foi o resultado principal desse processo. A enorme quantidade de trabalhadores encontrou-se cada vez mais obrigada a vender sua força de trabalho para os indivíduos/famílias, cujo poder de compra desses serviços decorre da baixa remuneração paga pelos mesmos e da desigual distribuição de renda. É fato incontestável que nem todas essas ocupações são caracterizadas por baixa qualificação e remuneração. Entretanto, é inegável que tais atributos marcam parte predominante delas.

É justamente na menor importância do setor industrial que reside a principal explicação do movimento de maior precarização de nosso mercado de trabalho. A destruição da base de trabalho assalariado nas grandes empresas/setor público joga para o PMS-NC a responsabilidade maior de responder pelo problema de absorção de mão-de-obra, fazendo com que um volume crescente de trabalhadores disputem uma mesma renda disponível ou que cresce de maneira desproporcionalmente mais lenta. O comportamento dos níveis de remuneração tende a ter um comportamento inverso ao crescimento de novas oportunidades ocupacionais no PMS-NC. Por outro lado, a lógica da racionalização econômica corrói também os salários tanto nas grandes empresas como no setor público. Observa-se, portanto, uma tendência de redução da remuneração do trabalho nos diversos segmentos de atividade econômica, fato que coloca em questão a possibilidade de mudanças sistemáticas e positivas no perfil de qualificação da mão-de-obra brasileira. Nesse sentido, apesar da importância dos esforços em favor da qualificação realizados no país nesses últimos anos, conclui-se que a nova dinâmica econômica referenda o perfil de baixa qualificação da mão-de-obra nacional, ratificando a péssima distribuição de renda e agravando a estrutura social historicamente desigual. Essa tendência, portanto, não sinaliza que as transformações em curso possam constituir uma economia mais competitiva e fundada em setores mais dinâmicos tecnologicamente e um perfil mais positivo de emprego e renda do país. 


\section{REFERÊNCIAS BIBLIOGRÁFICAS}

ABRAMO, L. (1996) Nuevas tecnologias y relaciones laborales en America Latina, Ilpes, Santiago de Chile.

ALDENDERFER, M. \& BLASHFIELD, R. (1984) “Cluster analysis”, Series Quantitative Applications in the Social Sciences, 44, Sage University Paper, Newbury Park.

ALMEIDA, J. (1974) “Industrialização e emprego no Brasil”, IPEA, Coleção Relatórios de Pesquisa 24, Brasília.

BALTAR, P. \& DEDECCA, C. (1995) "Notas sobre o mercado de trabalho na industrialização restringida”, Anais do Encontro Nacional da ABET, São Paulo.

BIELSCHOWSKY, R. \& STUMPO, G. (1995) “Empresas transnacionales y cambios estructurales en la industria de Argentina, Brasil, Chile y México", Revista de la Cepal, 55, Santiago.

BNDES (1999) "Fusões e aquisições no Setor de Alimentos", Informe Setorial,15, Abril.

BONELLI, R. \& FONSECA, R. (1998) "Ganhos de produtividade e de eficiência: novos resultados para a economia brasileira”, Pesquisa e Planejamento Econômico, 28(2), IPEA, Brasília.

BONELLI, R. (1996) Produtividade Industrial nos anos 90: controvérsias e quase-fatos, IPEA (mimeo.), Rio de Janeiro.

CACCIAMALI, M.C. (1983) Setor informal e formas de produção, IPE-USP, São Paulo.

CARVALHO, P.G. \& FEIJÓ, C.A. (1999) Produtividade industrial no Brasil: o debate recente e as fontes de dados (mimeo.), Rio de Janeiro.

CHANDLER, A. (1990) Scale and Scope. The dynamics of industrial capitalism. Harvard University Press, Cambridge.

CNI/CEPAL (1997) Investimentos na indústria brasileira 1995-99, CNI/CEPAL, Rio de Janeiro.

CNI/SENAI (1998) “Modernização, emprego e qualificação profissional”, CNI/SENAI, Rio de Janeiro.

CONSIDERA, C. (1998) "Produto, emprego e produtividade industriais; o que se pode aprender das novas contas nacionais?”, Mercado de Trabalho, Conjuntura e Análise, (3)7, Rio de Janeiro.

COUTINHO, L. \& FERRAZ, J.C. (1994) Estudo da competitividade da indústria brasileira, Papirus/ Edunicamp, Campinas.

CRIVISQUI, E. (1998) “Seminário de métodos estatísticos multivariados aplicados às ciências humanas”, Instituto de Economia/Unicamp-Université Libre de Bruxelles (Programme Presta), Material Didático (mimeo.), Campinas.

DEDECCA, C.S. \& BALTAR, P. (1998) “Mercado de trabalho e informalidade nos anos 90”, Estudos Econômicos, Número Especial, FEA-USP, São Paulo.

DEDECCA, C.S. \& ROSANDISKI, E. (1998) "Reorganização econômica, emprego e qualificação", Anais do XXVI Encontro Nacional de Economia, Vitória, Dezembro.

DEDECCA, C.S. \& ROSANDISKI, E.N. (1997) "Retratação do nível e na estrutura do emprego formal brasileiro - 1989-93”, Anais do XXV Encontro Nacional de Economia, vol. 1, Recife, Dezembro.

DEDECCA, C.S. (1990) Dinâmica econômica e mercado de trabalho urbano: uma abordagem da Região Metropolitana de São Paulo, IE-Unicamp (Tese de Doutoramento), Campinas.

DEDECCA, C.S. (1996) “Desemprego e regulação no Brasil hoje”, Cadernos Cesit, n. 20, IE-Unicamp, Campinas.

DEDECCA, C.S. (1998) “Mercado e relações de trabalho no Brasil”, XXII Congresso Internacional (Anais), Latin American Studies Association (Lasa), Chicago, Setembro.

DEDECCA, C.S. (1998) “O desemprego e o seu diagnóstico no Brasil hoje”, Revista de Economia Política, Janeiro-Março, Editora 34, São Paulo.

DEDECCA, C.S. (1999a) Produtividade, emprego e salários na indústria de transformação, IE-Unicamp (mimeo.), Campinas (ensaio submetido ao XXVII Encontro Nacional de Economia, ANPEC, 1999).

DEDECCA, C.S. (1999b) Racionalização e trabalho no capitalismo avançado, Editora do Instituto de Economia, Unicamp, Campinas. 
DUVAL, G (1998) L'entreprise efficace. À l'heure de Swatch et McDonald's, Alternatives Economiques/ Syros, Paris.

FEIJÓ, C.A. \& CARVALHO, P.G. (1999) O debate sobre a produtividade industrial e as estatísticas oficiais (mimeo.), Rio de Janeiro.

GORDON, D. (1996) Fat and mean, the corporate squeeze of working American and the myth of managerial downsizing, The Free Press, Nova York.

HENRIQUE, W. (1999) O Capitalismo Selvagem, um estudo sobre a desigualdade no Brasil, IE-Unicamp (Tese de Doutoramento), Campinas.

KUPFER, D. (1998) “Trajetórias de Reestruturação da Indústria Brasileira”, Boletim de Conjuntura, 18(2), Julho, IE/UFRJ, Rio de Janeiro

LEWIS, A.W. (1969) "O desenvolvimento econômico com oferta ilimitada de mão de obra”, in A.N.

Agarwala \& S.P. Singh, A economia do subdesenvolvimento, Forense, Rio de Janeiro.

LORINO, P. (1991) L'economiste et le manageur, La Decouverte, Paris.

PENROSE, E. (1980) The theory of the growth of the firm, Oxford, Londres.

SABÓIA, J. (1986) “Transformações no mercado de trabalho no Brasil durante a crise 1980-83", Revista de Economia Política, 6(3), Brasiliense, São Paulo.

SALM, C. \& EICHENBERG, L.C. (1989) "Tendencias de la integración en el mercado de trabajo brasileño", Revista de la Cepal, 39, Santiago, Chile.

SALM,C. (1997) "Produtividade na Indústria Brasileira: questões metodológicas e novas evidências empíricas", Pesquisa e Planejamento Econômico, 27(2), Brasília.

SINGER, P. (1971) "Força de trabalho no Brasil”, Cebrap, Caderno n. 3, São Paulo.

SOUZA, P.R. (1980) A determinação do emprego e dos salários em economias atrasadas, IFCH-Unicamp (Tese de Doutoramento), Campinas.

STREECK, W. (1992) Social Institutions and Economic Performance, Sage, London.

TOKMAN, V. (1978) "Las relaciones entre los sectores formal e informal — uma exploración sobre su naturaleza”, Revista de la Cepal, 5, Santiago de Chile.

WILLIAMSON, O. (1996) "La lógica de la organización económica”, in O. Williamson \& S.G. Winter, La naturaleza de la empresa, orígenes, evolución y desarrollo, Fondo de Cultura Económica, México. 